\title{
Evaluation of Ultrasonic Nonlinear Characteristics in Heat-Treated Aluminum Alloy (Al-Mg-Si-Cu)
}

\author{
JongBeom Kim ${ }^{1}$ and Kyung-Young Jhang ${ }^{2}$ \\ ${ }^{1}$ Graduate School of Mechanical Engineering, Hanyang University, Seoul 133-791, Republic of Korea \\ ${ }^{2}$ School of Mechanical Engineering, Hanyang University, Seoul 133-791, Republic of Korea \\ Correspondence should be addressed to Kyung-Young Jhang; kyjhang@hanyang.ac.kr
}

Received 19 July 2013; Revised 7 October 2013; Accepted 21 October 2013

Academic Editor: Young Soo Choi

Copyright (c) 2013 J. Kim and K.-Y. Jhang. This is an open access article distributed under the Creative Commons Attribution License, which permits unrestricted use, distribution, and reproduction in any medium, provided the original work is properly cited.

\begin{abstract}
The nonlinear ultrasonic technique has been known to be more sensitive to minute variation of elastic properties in material than the conventional linear ultrasonic method. In this study, the ultrasonic nonlinear characteristics in the heat-treated aluminum alloy $(\mathrm{Al}-\mathrm{Mg}-\mathrm{Si}-\mathrm{Cu})$ have been evaluated. For this, the specimens were heat treated for various heating period up to 50 hours at three different heating temperatures: $250^{\circ} \mathrm{C}, 300^{\circ} \mathrm{C}$, and $350^{\circ} \mathrm{C}$. The ultrasonic nonlinear characteristics of each specimen were evaluated by measuring the ultrasonic nonlinear parameter $\beta$ from the amplitudes of fundamental and second harmonic frequency components in the transmitted ultrasonic wave. After the ultrasonic test, tensile strengths and elongations were obtained by the tensile test to compare with the parameter $\beta$. The heating time showing a peak in the parameter $\beta$ was identical to that showing critical change in the tensile strength and elongation, and such peak appeared at the earlier heating time in the higher heating temperature. These results suggest that the ultrasonic nonlinear parameter $\beta$ can be used for monitoring the variations in elastic properties of aluminum alloys according to the heat treatment.
\end{abstract}

\section{Introduction}

To evaluate material degradation, destructive tests such as tensile test, impact test, and bending test are commonly used. However, the destructive tests require preparation of specimens separately from the operating structures and the specimens cannot be reused after test. Therefore, in order to save time and cost, the nondestructive evaluation technique is preferred.

Ultrasonic method is a common nondestructive method to evaluate the material degradation, since the propagation characteristics of ultrasonic wave is very closely associated with the elastic properties of material [1]. Generally, when the material is degraded, the elastic property of material will be changed, so that if we can monitor the change of elastic properties, then the degradation can be evaluated. For this purpose, most of ultrasonic methods measure the sound velocity or attenuation of amplitude: the linear elastic constant can be estimated by measuring the longitudinal wave velocity and the shear wave velocity [2]. Also, the correlation between the attenuation of ultrasonic wave and the microstructural change such as phase transformation or grain size growth has been reported [3]. And resonant frequency is dependent on the elastic properties of material as well. So, the linear elastic constant also can be estimated by using resonant frequency method [4].

Nevertheless, those techniques are still less sensitive to the minute degradation affected by precipitation or dislocation [5]. Thus, those conventional ultrasonic methods will not be able to evaluate the degradation induced by heat treatment in aluminum alloy effectively, since the thermal degradation in aluminum alloy by heat treatment is generally known to be related to the behavior of precipitation [6].

On the other hand, the nonlinear ultrasonic technique has been considered as a potential method since it has higher sensitivity to the minute degradation $[7,8]$. When an ultrasonic wave is transmitted in a material, the waveform is distorted by the nonlinear elastic property of material and the harmonic waves are generated. The nonlinear ultrasonic technique uses this nonlinear ultrasonic effect to evaluate 


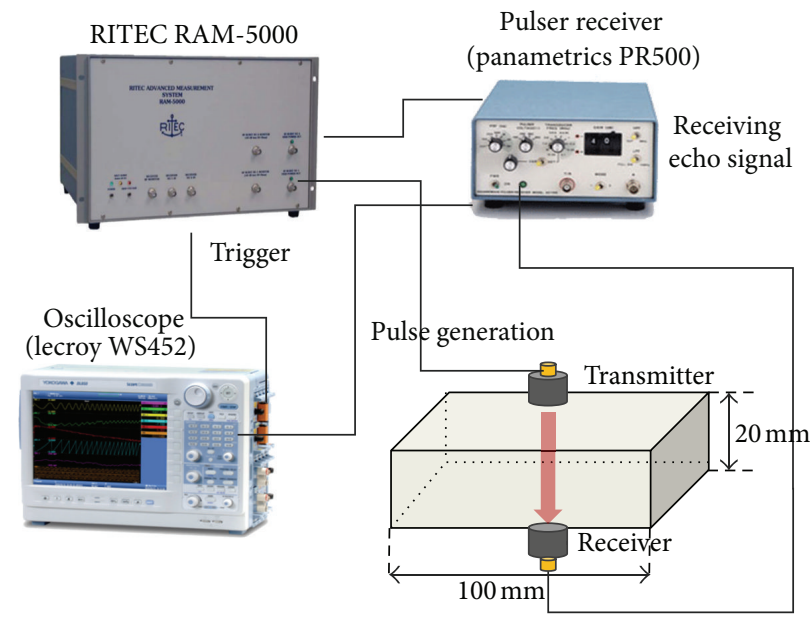

FIGURE 1: Experimental system to measure the ultrasonic nonlinear parameter.

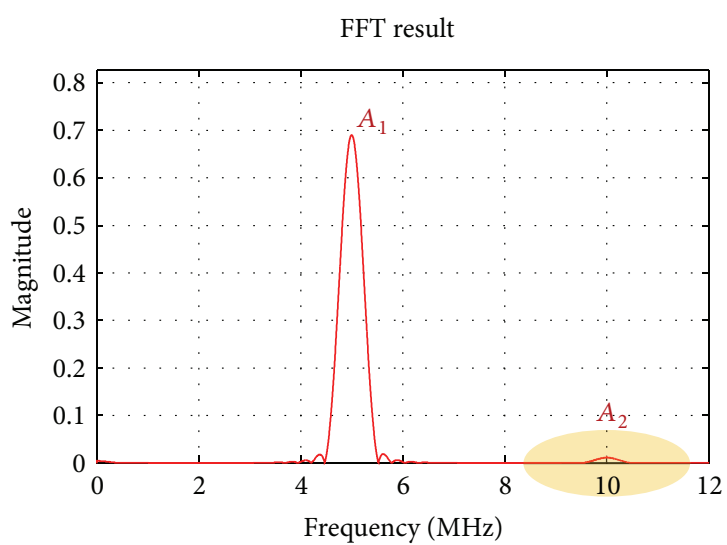

(a)

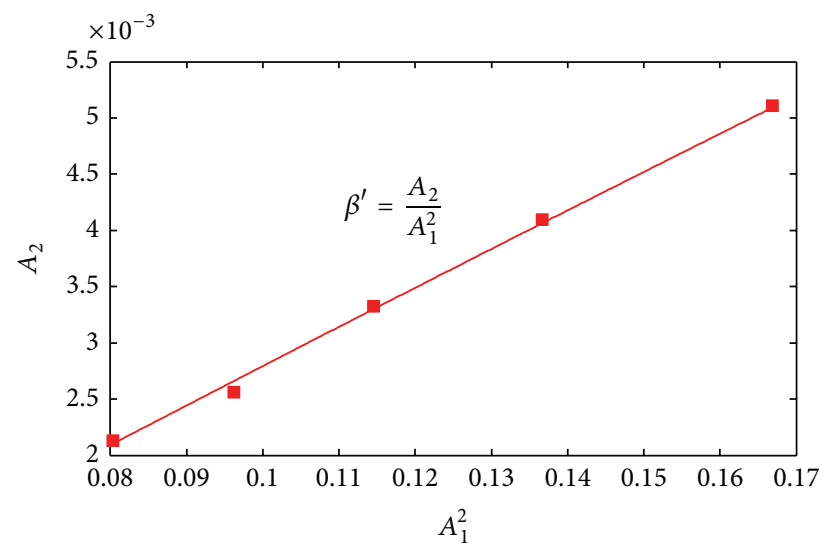

(b)

Figure 2: (a) Magnitude spectrum of the received signal and (b) experimental result to show the dependency of the second-harmonic amplitude on the power of fundamental frequency component.

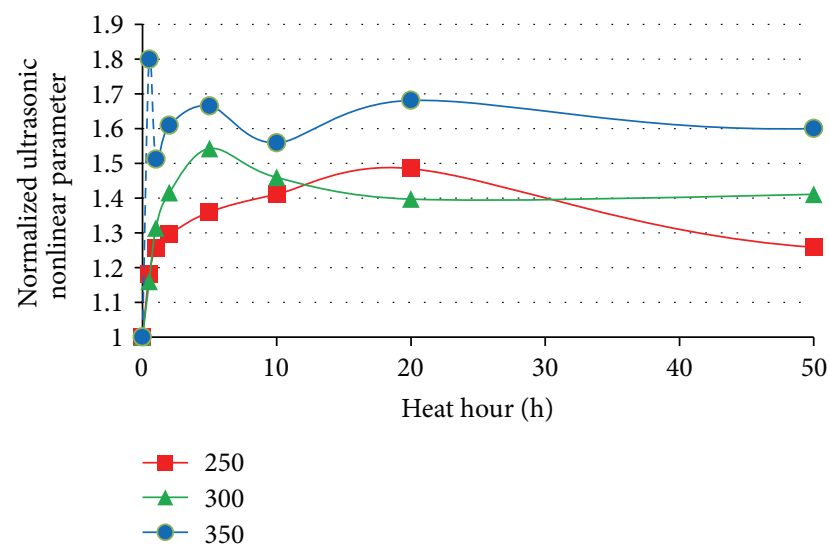

FIGURE 3: The ultrasonic nonlinear parameter obtained from three heating temperatures $\left(250^{\circ} \mathrm{C}, 300^{\circ} \mathrm{C}\right.$, and $\left.350^{\circ} \mathrm{C}\right)$, where the data was normalized by the value of ultrasonic nonlinear parameter obtained from no heat-treated specimen. changes in elastic property of material, which measures the ultrasonic nonlinear parameter $\beta$ defined by the ratio of the second-order harmonic amplitude and the power of fundamental frequency component $[7,9]$. The ultrasonic nonlinear parameter is related to the nonlinear elastic constants $[10$, 11], which is expected to be more sensitive to the minute degradation of material than the linear elastic constant.

This paper is to demonstrate the effectiveness of ultrasonic nonlinear parameter for the evaluation of thermal degradation in the heat treated aluminum alloy (Al-Mg-Si$\mathrm{Cu}$ ). For this purpose, the specimens were heat treated for various heating periods up to 50 hours $(1,2,5,10,20$, and 50) at three different heating temperatures: $250^{\circ} \mathrm{C}, 300^{\circ} \mathrm{C}$, and $350^{\circ} \mathrm{C} .5 \mathrm{MHz}$ tone burst longitudinal wave was used to measure the ultrasonic nonlinear parameter. The amplitudes of $5 \mathrm{MHz}$ and $10 \mathrm{MHz}$ components of the received signal were estimated by using (fast Fourier transform) FFT to obtain the ultrasonic nonlinear parameter. After the ultrasonic test, 


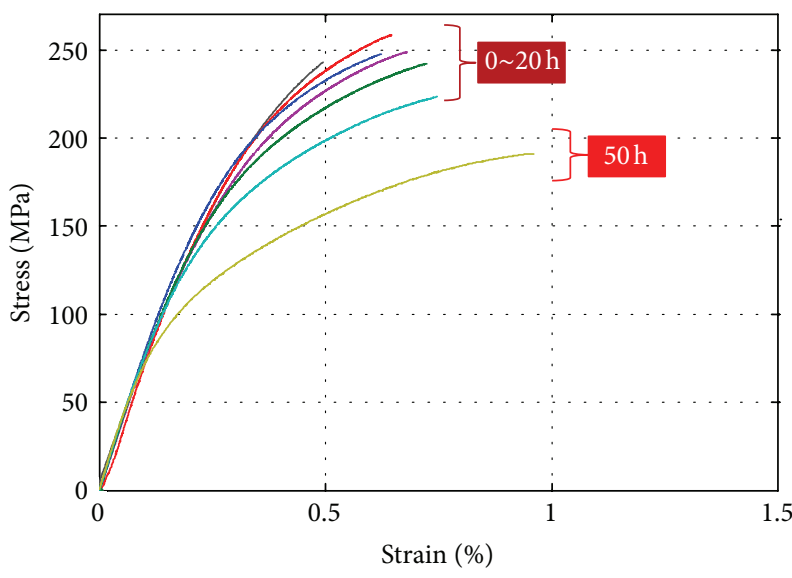

(a)

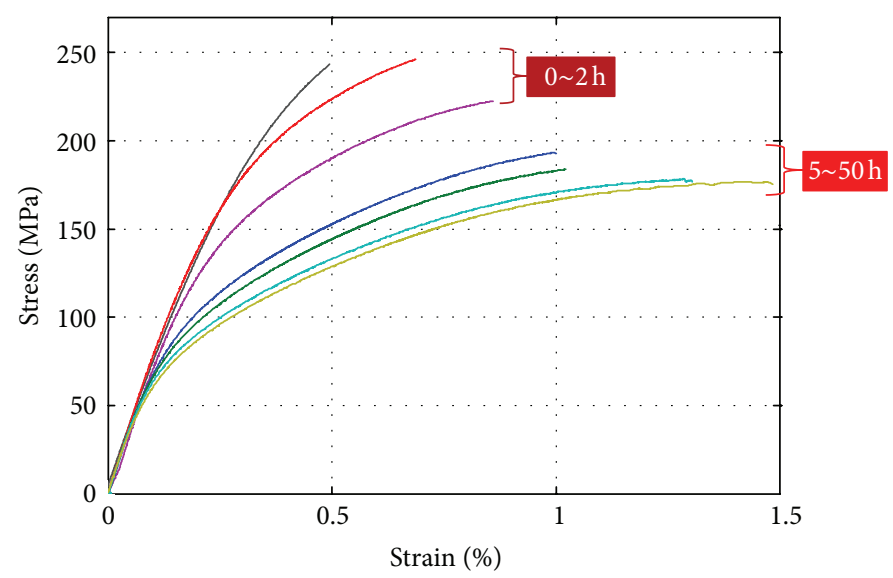

(b)

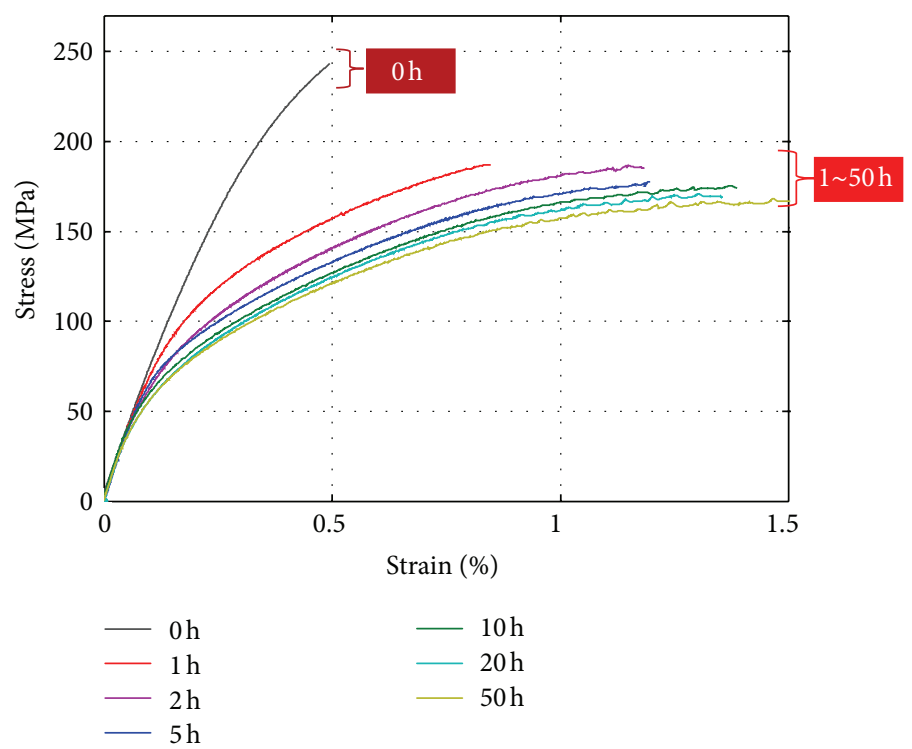

(c)

FIgURE 4: Stress-strain curve obtained from the tensile test for three heating temperatures: (a) $250^{\circ} \mathrm{C}$, (b) $300^{\circ} \mathrm{C}$, and (c) $350^{\circ} \mathrm{C}$.

tensile strengths and elongations were obtained by the tensile test to be compared with the parameter $\beta$.

\section{Ultrasonic Nonlinear Parameter}

To evaluate the ultrasonic nonlinear characteristics, a singlefrequency ultrasonic wave is launched into the specimen, and the signal of the ultrasonic wave transmitted through the material is received. In this process, the single-frequency ultrasonic wave is distorted due to the elastic nonlinearity and the second harmonic wave is generated. Thus, the received signal is composed of not only the fundamental frequency wave but also the second harmonic wave. The measurement of harmonic generation for microstructural characterization is typically aimed at determining the value of ultrasonic nonlinear parameter $\beta$ defined as follows:

$$
\beta=\frac{8 A_{2}}{A_{1}^{2} k^{2} x},
$$

where $A_{1}$ and $A_{2}$ are the amplitudes of fundamental wave and the second harmonic wave, respectively, $k$ is the wave number, and $x$ is the wave propagation distance. In our experiments, since $k$ and $x$ are constants, the quantity $\beta^{\prime}$ is measured as follows [12]:

$$
\beta \propto \beta^{\prime}=\frac{A_{2}}{A_{1}^{2}} .
$$

\section{Experimental Procedure}

The material of specimen is aluminum casting alloy, and its chemical proportion is shown in Table 1 . 


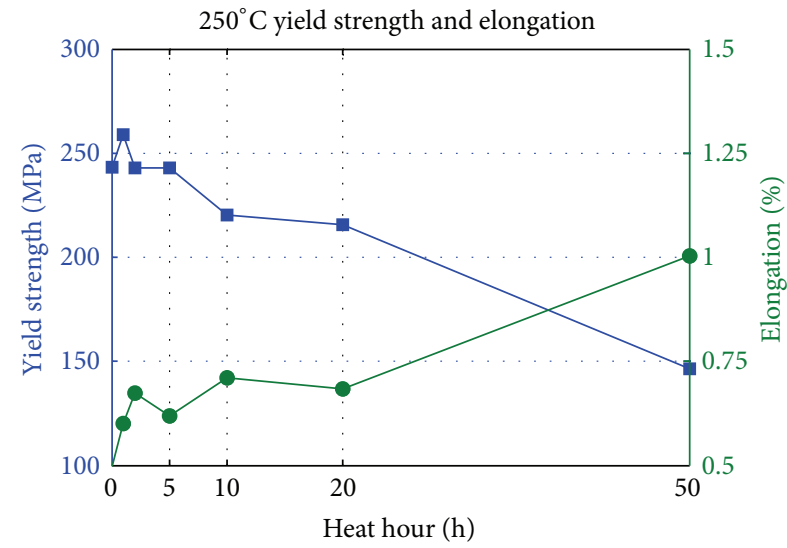

(a)

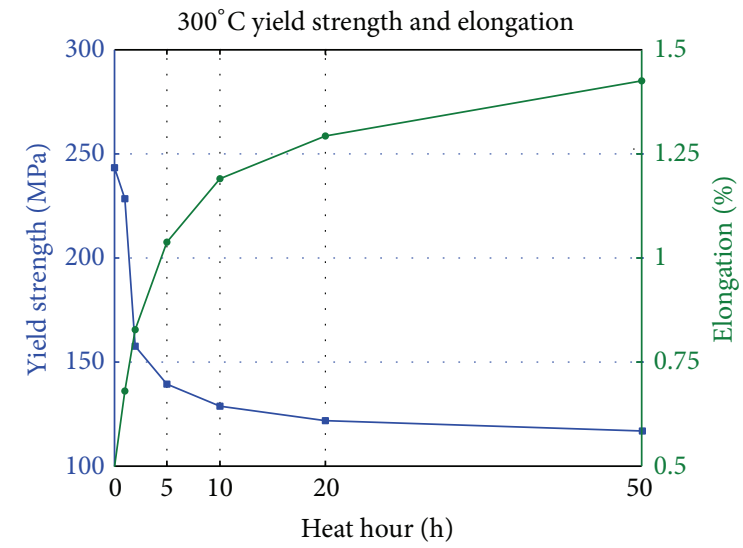

(b)

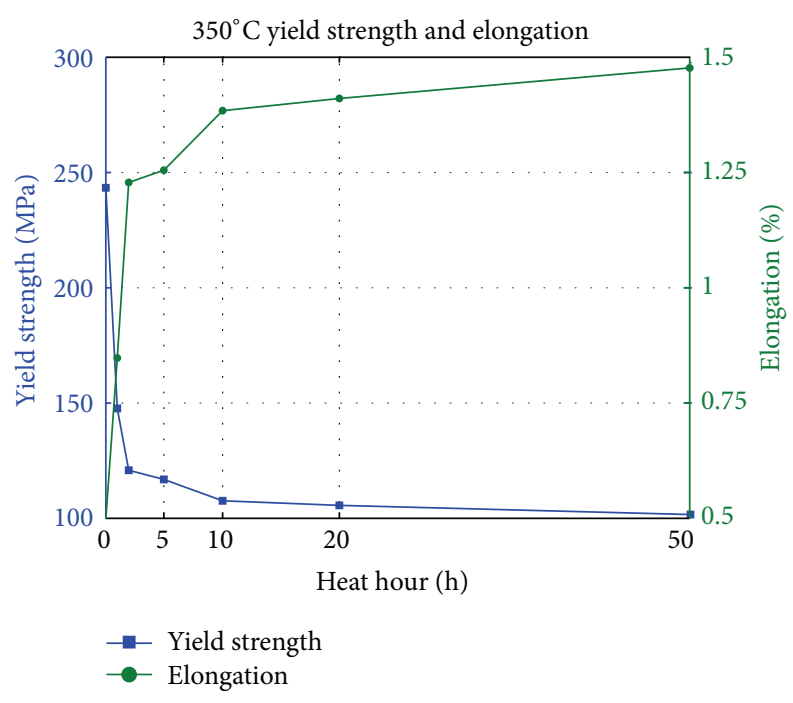

(c)

Figure 5: Yield strength and elongation obtained from the result of the tensile test for three heating temperatures: (a) $250^{\circ} \mathrm{C}$, (b) $300^{\circ} \mathrm{C}$, and (c) $350^{\circ} \mathrm{C}$.

TABLE 1: Chemical proportion of aluminum alloy (in wt\%).

\begin{tabular}{lccccccc}
\hline & $\mathrm{Al}$ & $\mathrm{Si}$ & $\mathrm{Ni}$ & $\mathrm{Cu}$ & $\mathrm{Zn}$ & $\mathrm{Mg}$ & $\mathrm{Fe}$ \\
\hline $\begin{array}{l}\text { Chemical } \\
\text { proportion (\%) }\end{array}$ & 77.0 & 13.8 & 1.11 & 3.69 & 3.14 & 0.90 & 0.36 \\
\hline
\end{tabular}

The size of specimen is $100 \mathrm{~mm} \times 100 \mathrm{~mm} \times 20 \mathrm{~mm}$. We prepared 18 specimens heattreated in 18 different heating conditions, three different heating temperatures $\left(250^{\circ} \mathrm{C}, 300^{\circ} \mathrm{C}\right.$, and $\left.350^{\circ} \mathrm{C}\right)$, and six different heating period $(1 \mathrm{H}, 2 \mathrm{H}, 5 \mathrm{H}$, $10 \mathrm{H}, 20 \mathrm{H}$, and $50 \mathrm{H}$ ) at each heating temperature. This heat treatment is a kind of accelerated reliability test condition to generate degradation in the tensile properties. Including an intact specimen without heat treatment, the total number of specimen is 19 .
In experiment, a measurement system with contact transducers was constructed as shown in Figure 1. Signal control is mainly based on the high power pulser (RAM 5000, RITEC, USA) that drives a transmitter. Transmitting frequency was set to $5 \mathrm{MHz}$, so that a $5 \mathrm{MHz}$ narrowband transducer is used as the transmitter. The receiver detects the ultrasonic wave transmitting the specimen. A $10 \mathrm{MHz}$ narrowband transducer was used as the receiver to detect second harmonic wave sensitively.

In order to measure the parameter $\beta^{\prime}$, the amplitude of the fundamental frequency component and the secondharmonic amplitude were obtained by FFT of the received signal as shown in Figure 2(a). Figure 2(b) shows the relationship between $A_{1}^{2}$ and $A_{2}$, which is obtained by increasing the input power for the intact specimen before the heat treatment. We can see clearly the linear relationship satisfying (2), and then the ultrasonic nonlinear parameter $\beta^{\prime}$ is determined 


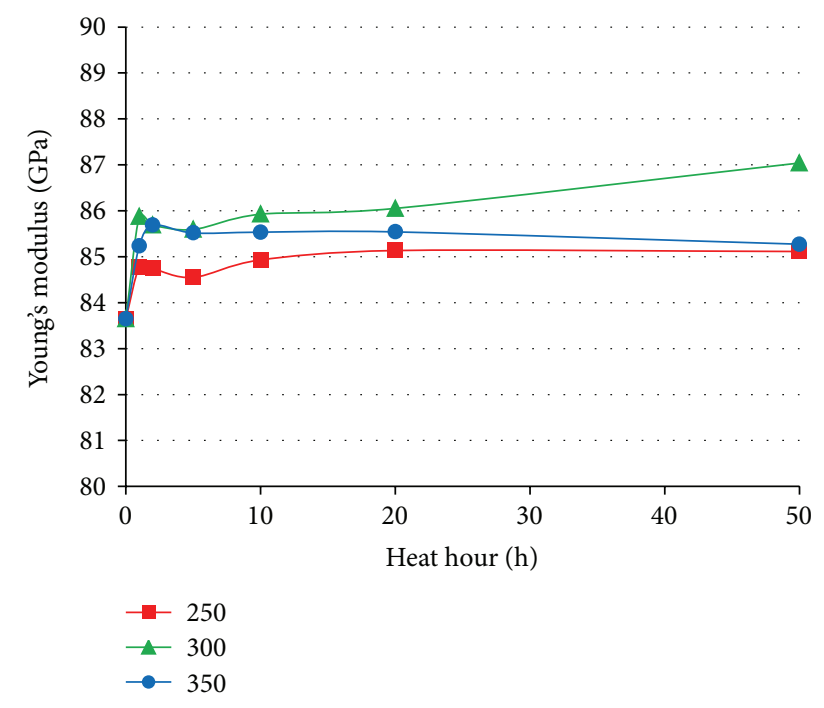

FIGURE 6: Young's modulus obtained by ultrasonic measurement of longitudinal wave velocity and shear wave velocity for three heating temperatures: (a) $250^{\circ} \mathrm{C}$, (b) $300^{\circ} \mathrm{C}$, and (c) $350^{\circ} \mathrm{C}$.

from the slope of the fitted line. For all specimens, we measured the ultrasonic nonlinear parameters in this way.

\section{Results}

Figure 3 shows the ultrasonic nonlinear parameter obtained for all specimens. Three curves are corresponding to three heating temperatures $\left(250^{\circ} \mathrm{C}, 300^{\circ} \mathrm{C}\right.$, and $\left.350^{\circ} \mathrm{C}\right)$, where the data was normalized by the value of ultrasonic nonlinear parameter obtained from the intact specimen. Maximum fluctuation in the repetition of measurement was less than $3 \%$. Results showed that a typical peak appeared; that is, at $250^{\circ} \mathrm{C}$ heating temperature the peak appeared at 20 -hour heat (48.5\% increase as compared with intact specimen), and in $300^{\circ} \mathrm{C}$ heating temperature the peak appeared at 5-hours heat (54.3\% increase as compared with intact specimen). From these results, it is expected that the peak appeared earlier in the higher heating temperature. At $350^{\circ} \mathrm{C}$ heating temperature, however, we could not see a peak earlier than 5hours heat. We can predict only that the peak of ultrasonic nonlinear parameter might occur earlier than 1-hour heat. The data shown in dotted line in the figure is just hypothetical.

Figure 4 shows the stress-strain curves obtained from the tensile test. We can see a dramatic change at some heattreatment hours. That is, at $250^{\circ} \mathrm{C}$ and $300^{\circ} \mathrm{C}$ heating temperatures, the stress-strain curves were dramatically changed at heat treatment time between 20 and 50 hours (16.5\% increase of elongation, $32.2 \%$ decrease of yield strength) and between 2 and 5 hours (11.7\% increase of elongation, 31.0\% decrease of yield strength), respectively. These results showed that the heat treatment time causing drastic change of curvature in the stress-strain curve is very similar to the heat treatment time showing a peak in the ultrasonic nonlinear parameter. At $350^{\circ} \mathrm{C}$ heating temperature, such dramatic change appeared at heat treatment time between 0 and 1 hour $(38.7 \%$ increase of elongation, $72.1 \%$ decrease of yield strength) which means that the critical microstructural change already happened prior to 1 hour heat. This result proves our hypothesis that the first peak of ultrasonic nonlinear parameter may occurred earlier than 1-hour heat at $350^{\circ} \mathrm{C}$ heating temperature. From these, we can conclude that the first peak in the ultrasonic nonlinear parameter is strongly correlated with the drastic change of curvature in the stress-strain curve.

Figure 5 shows the changes in elongation and yield strength according to the heat treatment time, which were obtained from the tensile test. The increment of elongation and the decrement of yield strength are bigger at the higher heating temperature. Also, at the heating hours specifically mentioned perviously, the elongation drastically increased and the yield strength rapidly decreased.

Physically, the ultrasonic nonlinear parameter is related to the thrid order nonlinear elastic constant and this nonlinear elastic constant is very sensitive to the change in composition of material. The aluminum alloy tested in this study is the casting alloy ( $\mathrm{Al}-\mathrm{Mg}-\mathrm{Si}-\mathrm{Cu}$ ). Generally, this alloy is thermally aged when exposed to high-temperature environment, and the precipitations (such as $\mathrm{Al}_{2} \mathrm{Cu}, \mathrm{Mg}_{2} \mathrm{Si}$ ) are created and transformed, which is reduced to the change of elastic property. Resultantly, the curvature in the stress-strain curve varies. The ultrasonic nonlinear parameter detected well such variation. Contrarily, the linear elastic constant obtained from the conventional ultrasonic method based on the sound velocity measurement did not show any typical change according to the heat-treatment time and the heating temperature. Figure 6 shows the measurement result of the linear elastic constant (Young's modulus).

\section{Conclusions}

The ultrasonic nonlinear parameters in the heat-treated aluminum alloy ( $\mathrm{Al}-\mathrm{Mg}-\mathrm{Si}-\mathrm{Cu})$ specimens have been measured and its effectiveness to evaluate the critical change in the elastic properties due to the thermal aging at high temperature was demonstrated. Specimens were heat treated at three different heating temperatures $\left(250^{\circ} \mathrm{C}, 300^{\circ} \mathrm{C}\right.$, and $350^{\circ} \mathrm{C}$ ) with six different heat treatment periods $(1 \mathrm{H}, 2 \mathrm{H}$, $5 \mathrm{H}, 10 \mathrm{H}, 20 \mathrm{H}$, and $50 \mathrm{H}$ ). After the ultrasonic test, tensile strengths and elongations were obtained by the tensile test to compare with the ultrasonic nonlinear parameter.

A typical peak appeared in the measured ultrasonic nonlinear parameter according to the heating time at each heating temperature and this peak appeared earlier in the higher heating temperature. That is, in $250^{\circ} \mathrm{C}$ the peak appeared at 20-hours heat, and in $300^{\circ} \mathrm{C}$ the peak appeared at 5-hour heat. In $350^{\circ} \mathrm{C}$, such peak was expected to occur earlier than 1hour heating. From the tensile tests, these heating periods were found to be identical to those when the curvatures of stress-strain curve were dramatically changed with the rapid increment of elongation and the sharp decrement of yield strength.

From these, we can conclude that the first peak in the ultrasonic nonlinear parameter is strongly correlated with the drastic change of curvature in the stress-strain 
curve and that the nonlinear ultrasonic method is useful to evaluate the critical change of elastic property by thermal degradation in heat treated aluminum alloys. Note that the linear elastic constant measured by conventional ultrasonic method based on the sound velocity measurement did not show any critical change according to the heating time and the heating temperature.

\section{Acknowledgment}

This work was financially supported by the National Research Foundation of Korea (NRF) Grant funded by the Korean government (NRF-2013M2A2A9043241).

\section{References}

[1] S. H. Baek, T. H. Lee, C. S. Kim, and K. Y. Jhang, "Ultrasonic nonlinearity measurement in heat treated SA508 alloy: influences of grains and precipitates," Journal of the Korean Society for Nondestructive Testing, vol. 30, no. 5, pp. 451-457, 2010.

[2] M. Kikuchi, M. Takahashi, and O. Okuno, "Elastic moduli of cast Ti-Au, Ti-Ag, and Ti-Cu alloys," Dental Materials, vol. 22, no. 7, pp. 641-646, 2006.

[3] A. Badidi Bouda, S. Lebaili, and A. Benchaala, "Grain size influence on ultrasonic velocities and attenuation," NDT \& $E$ International, vol. 36, no. 1, pp. 1-5, 2003.

[4] MAGNAFLUX, Magnaflux Quasar 4000 Quality Test Systems, 2013, http://www.quasarintl.com/ndt-products.

[5] U. S. Park, I. K. Park, and C. S. Kim, "A study on the evaluation of material degradation for $2.25 \mathrm{Cr}-1 \mathrm{Mo}$ steel by ultrasonic measurements," Transactions of the Korea Society of Machine Tool Engineer, vol. 10, no. 3, pp. 61-67, 2001.

[6] P. Palanichamy, M. D. Mathew, S. Latha et al., "Assessing microstructural changes in alloy 625 using ultrasonic waves and correlation with tensile properties," Scripta Materialia, vol. 45, no. 9, pp. 1025-1030, 2001.

[7] K.-Y. Jhang, "Applications of nonlinear ultrasonics to the NDE of material degradation," IEEE Transactions on Ultrasonics, Ferroelectrics, and Frequency Control, vol. 47, no. 3, pp. 540-548, 2000.

[8] G. E. Dace, P. B. Thompson, and L. J. H. Brash, "Nonlinear acoustics, a technique to determine microstructural changes in material," in Review of Progress in Quantitative Nondestructive Evaluation, vol. 10, pp. 1685-1692, Plenum Press, New York, NY, USA, 1991.

[9] J. K. Na, J. H. Cantrell, and W. T. Yost, "Linear and nonlinear ultrasonic properties of fatigues 410Cb stainless steel," in Review of Progress in Quantitative Nondestructive Evaluation, vol. 15, pp. 1347-1351, Plenum Press, 1996.

[10] T. Kundu, Ultrasonic and Electromagnetic NDE for Structure and Material Characterization-Engineering and Biomedical Application, CRC Press, 2012.

[11] J.-Y. Kim, L. J. Jacobs, J. Qu, and J. W. Littles, "Experimental characterization of fatigue damage in a nickel-base superalloy using nonlinear ultrasonic waves," Journal of the Acoustical Society of America, vol. 120, no. 3, pp. 1266-1273, 2006.

[12] I. H. Choi, T. H. Lee, and K. Y. Jhang, "Evaluation of fatigue degradation using nonlinear ultrasonics," Review of Progress in Quantitative Nondestructive Evaluation, vol. 29, pp. 1433-1438, 2011. 

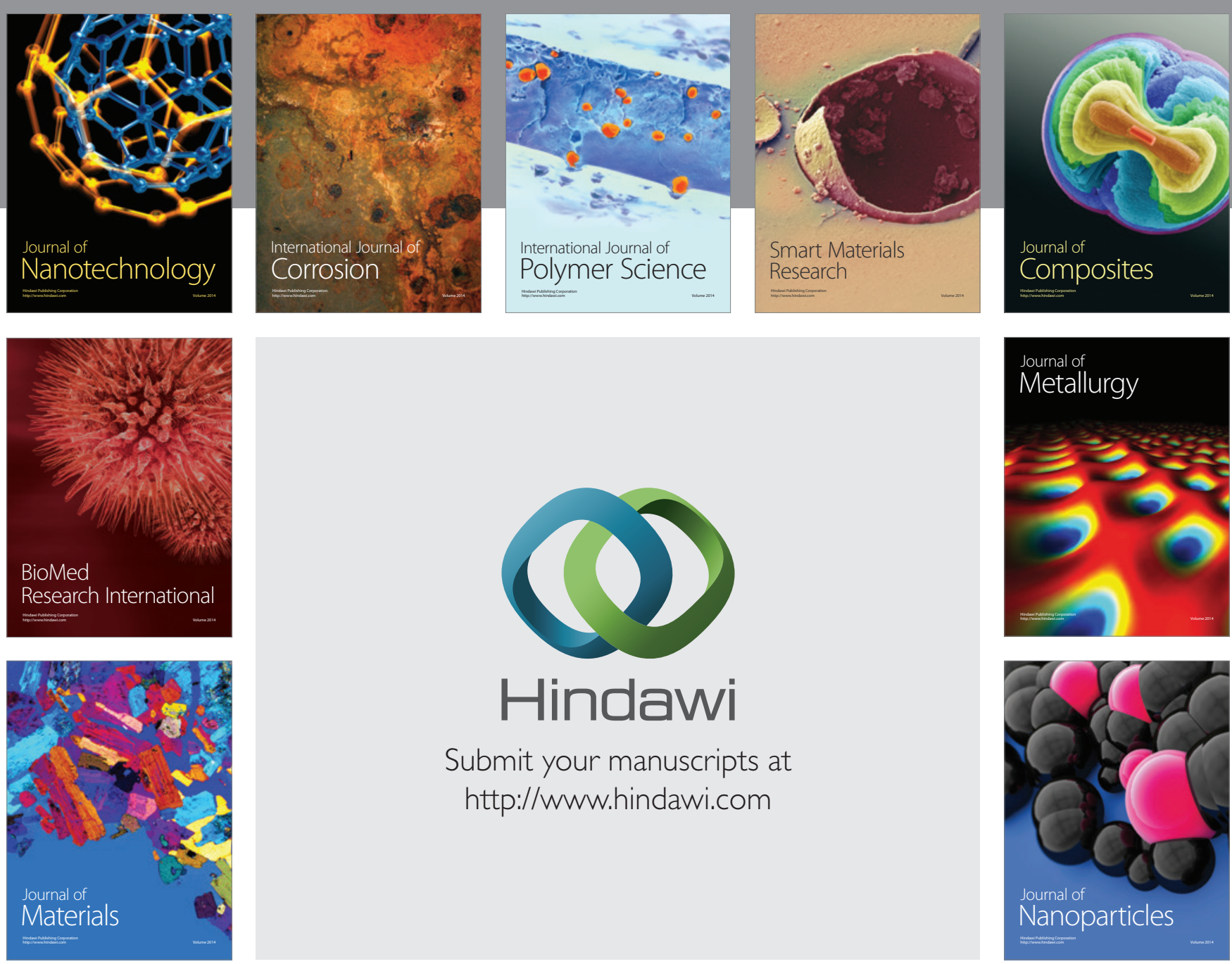

Submit your manuscripts at http://www.hindawi.com
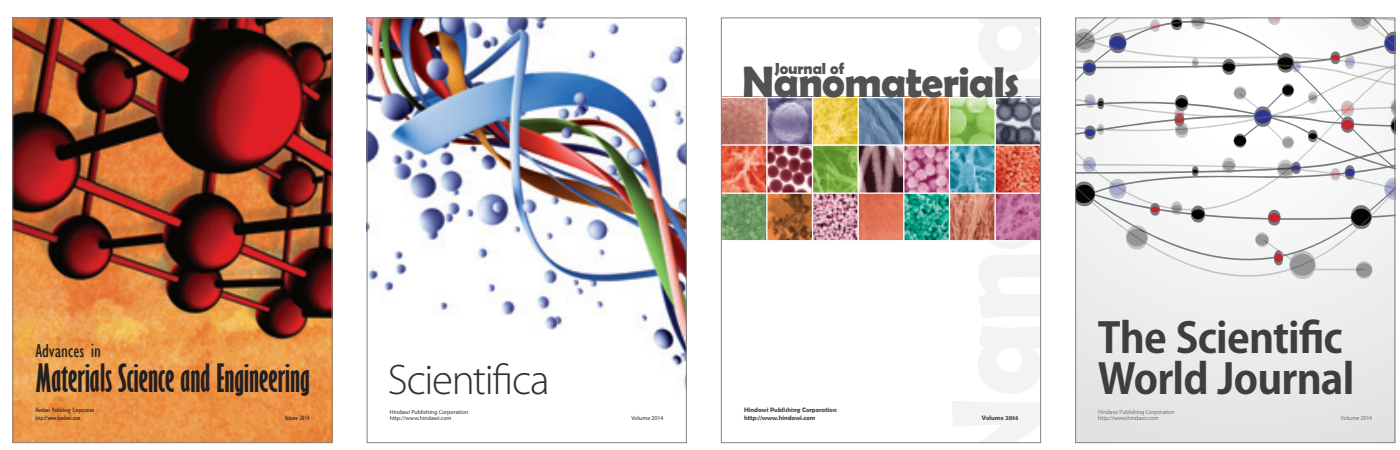

\section{The Scientific World Journal}
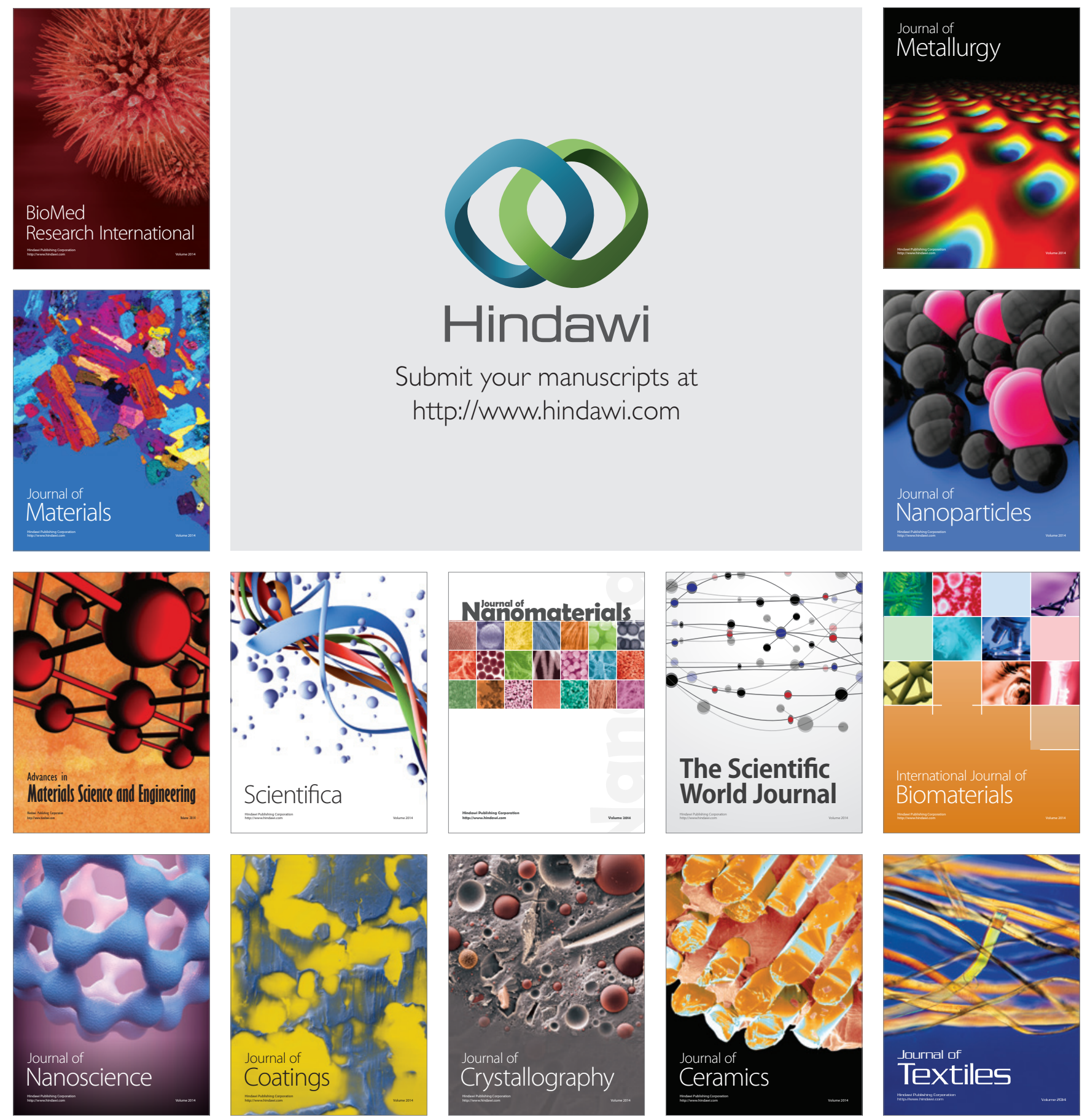